Media Industries $7.1(2020)$

\title{
Changing Business Models in the Media Industries
}

\author{
Nobuko Kawashima \\ DOSHISHA UNIVERSITY \\ Nkawashi [AT] mail.doshisha.ac.jp
}

\begin{abstract}
Media industries such as film, music, and publishing have traditionally relied on three models of revenue generation: payment by users for ownership of (or for access to) content, advertising fees, and the hybrid of these. For a long time, the models have largely been sustainable, but in recent decades advances in information and communication technologies and changes in consumer behavior have been so revolutionary that they pose unprecedentedly serious challenges to these models; the issue is no longer copyright infringement on its own, but how the industries respond to the changes in the market and find new, sustainable business models. This article discusses several of these new models, including Do-It-Yourself artist, expanded exploitation of copyright, diversification, dual-market model, and digital marketing for third-party marketers via social media and using own sites. Examples from Japan are drawn to illustrate the new developments.
\end{abstract}

Keywords: Media Industries, Business Model, Japan

\section{Introduction}

The second half of the twentieth century was a good time for the media industries, including: broadcasting, publishing, film, and music. Distributor/publisher/intermediary companies such as film studios, publishers, and record labels enjoyed comfortable business positions relying on two revenue sources: advertising and user payment, with varying degrees of dependence, depending on the industry. ${ }^{2}$ Firms from various sectors in the postwar era of economic development sought space and time for advertising, while consumer demand for information and entertainment increased. Many of the companies in the media industries could set premium prices for products, or obtain "rents," by creating artificial scarcity-for example, by setting release dates or controlling the quantity of physical products available 
on the market (see Note 2). ${ }^{3}$ The well-developed infrastructure for content distribution allowed the media majors to achieve economies of scale. Products distributed in physical packages (e.g., print media and music CDs) in particular could be "overpriced"; although the fixed cost of creating the original content could be high, the marginal cost of producing another unit was minimal.

However, such a business environment for the media industries, which was largely stable and comfortable despite the existence of fierce competition within individual markets, has been undermined since the late 1990s with the development of internet and information and communication technologies (ICT) and the widespread uptake of these technological advances by the general public. First, the print media industry (newspapers and magazines in particular) has suffered greatly. The spread of pirated copies and unlawful downloading of content online may be partially to blame, but at the same time people today find it decreasingly necessary to buy newspapers and magazines in print because the kind of information they traditionally looked for in them-news, gossip, fashion trends, vacant job positions-can be easily found and accessed online without paying. The recorded music industry, too, has suffered over the years, particularly due to the development of peer-to-peer, file-sharing technology and video-sharing websites such as YouTube. Eradicating unlicensed music available online turned out to be extremely difficult, eventually leading the record labels to provide free access to official videos on the video-sharing websites for the purpose of artist promotion.

Since the early 2000s, the emergence of social media, search engines, and major online services such as Amazon for e-commerce, Netflix for video streaming, and Spotify for music streaming, together with the spread of smartphones, has further threatened the conventional businesses of the media industries. Consumers are less and less willing to pay for content itself and often less immersed in it than they once were. They may be happy to pay for services that provide content, so long as access is convenient-providing the content when they want it, where they want it, and via the devices they habitually use. ${ }^{4}$ They also give priority to the ways in which they interact with content: by sharing it, discussing it with fans whom they may not personally know, and modifying it to create secondary works, often in collaboration with other amateur creators with whom they exchange in-progress works online. ${ }^{5}$

All of the above have driven a major transformation in the media industries. A wide range of academic disciplines have focused attention on specific aspects of and relevant issues concerning these changes in media production, distribution, and consumption. For example, a rich literature has developed on the rise of collaborative/participatory culture ${ }^{6,7}$ or "produsers." In contrast to digital optimists like Jenkins, more pessimistic commentators have pointed to a host of troubling issues such as increased centralization of corporate power, intensified commercialization of culture, and the rise of surveillance culture (see Note 2). A large number of articles and books have also been published on the need for regulation and other policy measures, including in the area of copyright, to adapt to the changing practices in media production and consumption. Digital transformation in the media industries has also been discussed among scholars concerned with its impact on the public interest and democracy, which news organizations have traditionally been viewed as bolstering through the provision of up-to-date, accurate, neutral, and well-researched information, investigation, and commentary. ${ }^{9}$ Economics and management studies of the media have been keen to 
investigate the impact of illegal music files on $\mathrm{CD}$ sales ${ }^{10}$ and the impact of streaming services on music industry revenue as a whole. ${ }^{11}$ Scholars have also researched the extent to which the diversity of content has increased or decreased as a result of digitized distribution. ${ }^{12,13}$

Many of the research findings show an overall decline in revenue in the traditional media industries and describe players' struggles to tackle this problem, but studies that directly discuss the "business model"-defined in this article as forms of value creation and appropriation $^{14}$-have been relatively few. A few exceptions exist on specific media industries. ${ }^{15-17}$ And a broader report titled "Changing Business Models in the Creative Industries," 18 commissioned by the UK Patent Office, studies six companies in the television, computer games, and music industries, providing useful details of changes in those industries. The overall conclusion of Searle (see Note 18), however, remains that the creative industries are in a state of business model experimentation, a situation brought about not necessarily by challenges to intellectual property (IP) but by other factors such as changes in consumer demand and behavior in the digital era. Although the individual cases described in these studies may be interesting, the overall picture does not exceed what we intuitively know. The lack of research into business models in the media industries may be partly due to the ambiguity of the term "business model"19 and to the speed at which new businesses constantly appear to disrupt existing business frameworks.

The purpose of this article is to review existing research and analyze new business models being used in the media industries to respond to the impacts of new ICT, changed user behavior, and globalization. Assuming that these factors must have impacted cost structures, production patterns, and distribution methods of media businesses, the article will focus on the ways in which the media industries in different sectors have understood and responded to changing consumer needs, identified or redefined market segments, delivered newly created value to consumers, and earned revenue in ways that can be sustained at least into the near future. Six new business models are identified. Some of the "new" models in fact represent only small, incremental "defensive" changes, while other, more disruptive changes are being driven by new giant IT platform operators. An implication of this is that the value of content created by traditional media may be relegated to the role of attracting consumers, whose aggregated profiles and behavior information form a valuable asset for any business engaged in digital marketing.

Although this article does not try to break new theoretical ground, its broad survey helps fill a gap in media industries research that discipline-based or sector-focused studies tend to be less good at. The article will also provide added value by using examples from Japanese media and entertainment businesses. Japanese popular culture is generally very strong in Japan's domestic market (see Kawashima ${ }^{20}$ on film), which is the second (music) or third (film, digital games) largest in the world, and has a significant presence in specific regions with keen fan bases (as seen, for example, with Japanese animé in North America, Europe, and Asia). Nonetheless, much less attention has been given to its business structures, models, and strategies than to its actual content by humanities and Japanese studies scholars in the English language literature. The reference to Japanese examples is not necessarily for the purpose of showing good practice, but it will help broaden the scope of media industries research by analyzing the ways in which one major media capital ${ }^{21}$ copes with the changing environment. 
The responses of Japanese (and other) media companies to changes in their business environment are, not surprisingly, mixed: Some are novel and forward-looking, or at least distinctive, whereas others are conservative, seeking to protect and maintain the status quo for the time being. In the following, I first present an overall picture of the business models conventionally employed in the media industries and discuss the challenges they face. I then analyze the strategies employed by media businesses to cope with changes, with examples drawn from Japan's music, animé (Japanese animation), and newspaper industries.

\section{Changing Business Models}

As mentioned above, until fairly recently the structure and value chains of the media industries were similar and relatively straightforward. They could rely on two major sources of revenue: payment by the user and advertising. The industries were supplier-led rather than customer-centric. In most cases, value chains were uncomplicated: Content was produced by artists, creators, authors, and production companies; commodified by commercial distributors such as publishers, film distributors, and record companies; and then handed over to retailers such as cinemas and shops. Newspapers were relatively self-sufficient, integrating the functions of content creation (information gathering and report writing), commodification (editing and printing), and distribution through their own dedicated sales networks. The players involved in each stage of the value chains were limited and fixed; new entrants might enter a market, but they only competed with incumbents rather than disrupting the existing order. To price "information" (i.e., content) is generally difficult, but pricing was not a major issue in these industries as prices-for admission to the cinema, to purchase a CD, book, or other product-were fixed within narrow ranges. Marketing largely targeted the mass through the placement of extensive advertising in the media, while the economies of scale enjoyed by the majors enhanced their power to control the market upstream and downstream (see Note 3).

As new digital ICT developed and spread, new businesses in the media industries have emerged. Hess ${ }^{22}$ summarizes the characteristics of online media (as opposed to print newspaper and conventional broadcasting) as being bidirectional (interactive) and multimediabased, which tends to appeal to today's consumers. With the additional trait of online media that Hess (see Note 22) identifies-low entry barriers to the market-the old media are severely contested and can no longer be assured of earning high profits from the traditional revenue sources. The observation of Hess can be applied more broadly to the media industries with which this article is concerned. Building on Hess (see Note 22), Table 1 stylizes the major characteristics of the conventional and new business models of the media industries. In some sectors, extreme, disruptive examples-even "gift economies," in which the exchange between producer and consumer is nonpecuniary-are developing. ${ }^{23}$ In others, several transitions can be observed, to which this article now turns.

\section{Model 1: Do-It-Yourself Artists}

We begin with the case of content creators cutting out intermediaries and connecting directly with consumers. Traditionally, professional artists/creators were the starting point 
Table 1. Comparison of Conventional and New Business Models of Media Businesses.

\begin{tabular}{|c|c|c|}
\hline & Conventional business model & New business models \\
\hline $\begin{array}{l}\text { Value-adding steps covered by } \\
\text { media companies }\end{array}$ & Content creation, distribution & $\begin{array}{l}\text { Management of content, operation } \\
\text { of digital space (apps, websites, } \\
\text { social media), alliance with various } \\
\text { sectors }\end{array}$ \\
\hline Value chain & $\begin{array}{l}\text { Fixed, controlled, supplier-led, } \\
\text { one-way }\end{array}$ & $\begin{array}{l}\text { Flexible, organic, user-centric, } \\
\text { interactive }\end{array}$ \\
\hline Value creation & Copyright exploitation & Multiplatform business \\
\hline Revenue source & User payment, advertising & $\begin{array}{l}\text { User payment, advertising, user } \\
\text { subscription fees, sale of user data }\end{array}$ \\
\hline Main partners & Promoter, retailer & $\begin{array}{l}\text { Content/service providers, } \\
\text { neighboring industries in the media } \\
\text { and elsewhere }\end{array}$ \\
\hline Market entry barriers & $\begin{array}{l}\text { High: initial investment of capital } \\
\text { required }\end{array}$ & Low \\
\hline Competition & Intra-market & Inter-market \\
\hline Role of creators & $\begin{array}{l}\text { Strong, but moderated by the } \\
\text { intermediary }\end{array}$ & $\begin{array}{l}\text { Direct connection with users, need } \\
\text { to be entrepreneurial }\end{array}$ \\
\hline Content creation & Reserved for the professionals & Open to all \\
\hline Role of consumers & Passive & Active \\
\hline Traits valued by consumers & Quality of content & $\begin{array}{l}\text { Social communication about } \\
\text { content, convenient access }\end{array}$ \\
\hline $\begin{array}{l}\text { Primary competences of media } \\
\text { companies }\end{array}$ & $\begin{array}{l}\text { Artistic/journalistic editing, } \\
\text { curation and distribution }\end{array}$ & $\begin{array}{l}\text { Aggregating content, algorithms } \\
\text { for matching content and users }\end{array}$ \\
\hline Control of the market & Strong & Weak \\
\hline Control of use & Strong & Weak \\
\hline Advertisers' interest & Mass marketing & Targeted marketing \\
\hline
\end{tabular}

Source. Adapted and expanded from Hess (see Note 22).

Note. The models are ideal types and do not necessarily describe specific industry sectors.

in the linear value chain, and they benefited in subsequent stages from the help of distributors and retailers. Because distributors and retailers are less profitable than they once were, and therefore less capable of returning profits to content creators, many creators have found it necessary to take advantage of new technologies and become more self-reliant. This is the background to the rise of the Do-It-Yourself (DIY) model. This model is particularly prominent among independent musicians, who cannot expect much support from major record 
labels as the labels concentrate marketing budgets on smaller numbers of signed artists (see Note 15). ${ }^{24}$

Seen in a positive light, musicians are now able to access a range of services for music production, distribution, promotion, and marketing offered at affordable prices through digital technologies and services. They can rent studios and hire technicians at costs that have been lowered by technological developments, with funds raised by crowdfunding. They can set up accounts on social media and create original websites where fans can download a piece of music for free if they register, leaving personal data for artists to utilize for future contact and market research. Information about where fans live aids efficient concert planning.

Some argue that these technological advancements have helped independent artists become more autonomous ${ }^{25}$ and entrepreneurial (see Note 15), and that they have changed the nature of relationships among artists, fans, and the music industry. ${ }^{26-28}$ Fans are seen to have new relationships with artists as "sponsors, co-creators of value, stakeholders, investors and filters" ${ }^{29}$ and to be increasingly involved with music making and marketing, particularly through social media. ${ }^{30}$ However, it is unclear whether DIY artists can gain access to major music distribution channels that may be mediated by new intermediaries who, for efficiency reasons, may have little interest in dealing with independent labels. ${ }^{31-33}$

\section{Model 2: Expanded Exploitation of Copyright}

For industries traditionally reliant on copyright exploitation in the form of reproducing original content in large quantities and earning revenue from selling it in the mass market (as seen, for example, in recorded music and book publishing), different rights that copyright holders are granted have started to carry more weight in terms of revenue production. For example, the right to make content accessible to the public (e.g., by streaming on the web) has assumed greater importance, although labels are finding streaming difficult to manage strategically. Music labels have started paying greater attention to the licensing of music for other media industries, such as film, television dramas and commercials, and digital games. ${ }^{34}$ The music pieces used in these media and entertainment products may be only small parts of songs in terms of duration, but they can command high fees from licensees. The resulting exposure is valuable as the marketing budgets of record labels are shrinking.

\section{Model 3: Diversification}

Similar to but broader than copyright exploitation is the use of IP to earn revenue in neighboring business areas. For example, characters originally developed in an animation movie may be utilized in digital games, graphic novels, toys, and other merchandise. Such multiplatform strategies have been in existence for a long time in media industries, but today they have grown so much that it is sometimes difficult to know in which media format a character was originally born. Also, multiplatform business is increasingly planned as such from the very beginning of character/story development so that it can simultaneously be launched in various forms.

Of particular importance in such a scenario, interestingly, is utilization of digital content for non-digital (live) purposes. For example, official music videos available for free on YouTube can enhance the popularity of the artist, allowing him/her to earn handsomely from concert 
tours. Today, the top-earning musicians in the global market derive a majority of their income from live performances, whereas their royalties from recorded music can be less than 5 percent of sales. ${ }^{35}$ Japanese animé song concerts (with voice-over artists as singers) are often held in large arenas that accommodate more than ten thousand fans and generate considerable income. Musicals and theater performances based on manga, animé, and games (commonly called 2.5-dimensional theater/musicals in Japan, as their source content is two-dimensional) are also blossoming in Japan.

Live performance has traditionally been seen as less profitable than recorded music sales because the number of tickets that can be sold is physically limited by the seating capacity of venues and the number of times an artist can perform per year. However, in today's digital age, people increasingly tend to place high value on non-digital, live experiences and are willing to pay for expensive tickets. In a similar vein, live (and recorded) showings of events at cinemas-the screening of theater performances and televised sports matches-have become popular as people desire to see these events not only on large screens with good sound effects but also together with other viewers to share the excitement and moments of joy. In terms of sheer numbers, the purchasers of tickets to live events and tangible ancillary goods may not add up to the equivalent of a mainstream mass market, but these live performance markets which in the past were seen as small and niche no longer remain so. Traditionally, record labels were not heavily involved in the live performance side or other aspects of musicians' activities, but now they aggressively try to gain a share of such new revenues by signing so-called 360-degree contracts with artists for fees. ${ }^{36}$

The business model changes discussed so far are not particularly innovative, as they mainly involve developing business areas that were previously neglected as relatively unimportant. The lack of novelty is evident in the fact that these strategies have long been adopted in the Japanese music industry. To start with, musicians are "employed" by management companies and receive a monthly salary. Practical arrangements and relationships may differ from one artist to another, but management companies (jimusho, discussed by Marx ${ }^{37}$ in detail) are in the business of maximizing the exposure of their artists under contract, basically taking all payments for the artists' activities and then paying remuneration to them that reflects their popularity and workload. Tie-in contracts with television dramas, films, and TV commercials have been common in the Japanese music industry since the late $1980 \mathrm{~s},{ }^{38}$ although these are not necessarily for the purpose of sharing fees between creative management companies and record labels, but rather for promoting recorded music and building the artists' brands. It has also been the case for decades that Japanese artists and idols are expected to be multitalented. This does not mean that they need to be professionally competent in all areas such as singing, dancing, and acting in film and television dramas, but it is crucial for them to appear on talk shows and variety programs on television and to be funny, chatty, clever, and accessible (see Galbraith and Karlin ${ }^{39}$ for the analysis of the idiosyncrasies of idol and celebrity culture in Japan).

In the last ten to fifteen years, a more innovative business model for idol groups has been established by an influential producer, Yasushi Akimoto. Akimoto has been in the entertainment business for decades as a producer and also a lyricist, and he has further cemented his dominant position in the Japan's entertainment industry by creating and producing the young female idol group AKB48 and its branches (see Craig ${ }^{40}$ for a detailed study of the group). 
Launched in 2005, AKB48 is based on the concept of "idols you can meet," and fans may become deeply involved in the process of the girls' growth from unpolished to more polished performers. AKB48 is made up of around one hundred girls, divided into four "teams" which can appear simultaneously in various locations-one way of actualizing the "idols you can meet" concept. One of the teams performs at the AKB48 Theater in Tokyo's Akihabara area every day. The theater is small, accommodating just 250 people, so obtaining tickets can be difficult, but those who are lucky enough to do so can see the girls up-close and begin to feel a connection and support them in their careers. Which girls sing on the group's singles and their position in the dance formations on stage are determined by various "buzz-generating" means, including an annual General Election in which fans who have purchased CDs are able to vote. The Election is a high-profile, nationally-televised event widely reported in the media. Avid fans buy multiple CDs-sometimes hundreds of the same title-so they can cast many votes for their favorite performers. CDs may also come with "hand-shaking session" tickets. Enthusiasts may buy multiple copies of CDs so as to lengthen the time allowed with their favorite girls at such events, as one ticket allows a contact of only some seconds. When members get older, they "graduate" and are replaced by younger girls. The large size of the group and the constant refreshment of its composition, it is said, allow everyone to find a favorite.

Based on the success of AKB48, sister groups have been set up in major cities of Japan, including Osaka, Nagoya, and Hakata. The franchise has also spread to Asia to include JKT48 in Jakarta, BNK48 in Bangkok, and DEL48 in Delhi. Unlike K-pop groups, Japanese idols of this kind are imperfect in performance, a "defect" which, however, is said to work well with the Japanese sense of aesthetics. The success of AKB48 has been phenomenal, with singles and albums selling more than one million units per title (a mark rarely achieved in Japan today); their single CDs have occupied the top of Japanese hit charts for over ten years (various statistics released by RIAJ). ${ }^{41}$

Criticism of Akimoto is abundant: He is accused of exploiting obsessive fans by luring them to excessive spending; taking advantage of young girls aspiring for fame, few of whom end up establishing long-lasting careers; and commodifying not only girls but also their music. However, it can be argued that Akimoto has saved the Japanese recorded music industry; the decline in its revenue-from 607.5 billion yen in 1998 to 304.8 billion in 2018-would surely have been much larger without Akimoto. As a result, Japan remains an outlier in terms of music distribution methods, with market sales still dominated by physical CDs and DVDs as opposed to digital sales and revenue from streaming services. The physical share of revenues is 79 percent (2018; see Note 41), in contrast to the global average of 25 percent. $^{42}$

Japan also has a male idol group culture, dominated by Johnny \& Associates, the country's largest talent agency. Established by the legendary Johnny Kitagawa in the 1960s, who remained active until his death at the age of 87 in 2019, Johnny's (as the agency is known) and its male idol groups have occupied a very important place in the popular entertainment world of Japan, particularly since the 1980s. Again, unlike K-pop male groups, none of the Japanese groups managed by Johnny's excels in singing or dancing, but their members look accessible, identifiable, familiar (see Note 39), and are interesting in talk shows and variety programs on television. Many appear in television dramas, films, and product advertisements. ${ }^{43,44}$ The level and scope of their exposure in every media and visual space are "far in excess of anything seen in contemporary Western pop music culture." ${ }^{45}$ Music CDs and DVDs 
of the groups managed by Johnny's, together with those of AKB48, have dominated the hit charts of Japanese music measured by CD sales in the last ten to fifteen years. What one might call a "no-online" policy of Johnny's strengthens its CD sales; visual images of Johnny's artists rarely appear online, few official social media accounts exist of any artist or group managed by Johnny's, and very little of the groups' music is commercially available online, either from iTunes or from Spotify. Fans therefore have to purchase music CDs, another contributing factor to the strength of packaged music sales in Japan.

While CD sales are managing to stop a further decline, the diversification strategy is spreading as a new business model in Japan with Sony Music as a possibly extreme case. The core business of Sony Music has been to produce CDs, DVDs, and music for online distribution, but Sony Music has been subsumed to just one division of Sony Music Entertainment Japan, Inc. (SMEJ), a holding company that now encompasses various entertainment sectors such as live concert management; animation production and its character business; management of artists, creators, and comedians; exhibition design with the use of augmented and virtual reality (AR and VR); and sports entertainment. It is unclear whether the holding company intends to cover any losses made by Sony Music with profits made by other group businesses or to more strategically integrate them for synergy/convergence effects. It should be noted that at the heart of this group is the animation-based company Aniplex Inc., whose business area has diversified from anime production to the production of musicals, concerts, figurines, apparel, and mobile games. (Digital games for PlayStation are handled by Sony Interactive Entertainment.) The contribution made by Aniplex to the total revenue of SMEJ is around half and is expected by investors to grow further.

\section{Model 4: Dual Markets}

A fourth business model being developed in the media industries can be seen in the transition of a B2C model (such as recorded music being sold by labels to consumers) to a "dualmarket" model. The dual-market model is best represented by the private broadcasting industry, whereby broadcast content attracts the attention of viewers/listeners, to which advertisers seek to expose their products. By attracting as large an audience as possible, broadcasters increase their value to advertisers, who compete for greater exposure. In this way, content production has effectively been subsidized by advertisers. Such a broadcasting model was predicted to become the standard model for the recorded music industry some years ago by Fox and Wrenn, ${ }^{46}$ who proposed that music be provided for free to consumers who, however, would need to tolerate intermittent advertising that funds music distribution. This is the major strategy of K-pop; its phenomenal global success comes largely from giving unlimited access to music videos free on YouTube and other social media while earning revenue from advertising, sponsorship by Korean manufacturers, and live concerts. ${ }^{47}$ Indeed, most of the content-related services on the web are ad-supported, including Spotify's free provision of music streaming, mobile game apps, web magazines, and news sites.

Social media, too, operates on the dual-market model, the only difference from the traditional media being that its content is mostly created by millions of amateurs for sharing (e.g., chat and photos) rather than by professional creators. For the business of social media, what matters is the size of the installed customer base and the frequency and length of service use by customers, as these affect the attractiveness of social media for advertisers. Similarly, 
for other platform operators such as Amazon, Google, Apple, and Netflix, the size of the customer base is very important as it affects the number of service/goods providers and their willingness to supply. In such a way, these businesses all operate two-sided markets in a networked economy: one for consumers and the other for advertisers and service/goods providers (wholesalers and retailers for Amazon, application developers for Google and Apple, and film distributors for Netflix). It is important for social media to make the interface user-friendly and encourage users to frequently return to their service, for which they have developed effective algorithms.

The relevance of the above discussion for the conventional media industries is that professionally-created content is also becoming attractive for social media and other IT platforms. It is well known that Amazon, originally and principally an e-commerce site, has increased value for customers and enhanced its brand by the launch of Prime Video, which is freely accessible to Amazon Prime members (together with other services offered to members). Prime Video offers a large selection of licensed video content as well as original content exclusive to Prime members. Content created by professionals in the media industries may also be found in social media as posted by the professionals themselves and as shared by users who find it elsewhere. A large number of people read tweets and reports posted by legacy media accounts. In this way, creative media content plays a pivotal role in the dual market of social media and IT platforms and may be a source of significant income for the media companies. In other words, while conventional media industries struggle to earn profits in their traditional way and through their own initiatives in the digital sphere, they actually are useful in the newly-developed space of social media and IT platforms, which act like some of the legacy media in operating the dual-market businesses.

\section{Model 5: Social Media-Based Digital Marketing for Third-Party Marketers}

It must be noted that the usefulness of the social media space for advertising derives not only from its large user base but also, and more importantly, from the opportunities for targeted marketing afforded by the enormous amounts of information social media collect about their users' demographics and online behavior (which in turn may be related to their offline behavior). This is related to the fifth business model that is emerging for the digitized media industries: selling customer data to third-party marketers keen to target potential consumers using social media or other websites. The educated public may now be aware of how much personal information they give away to Facebook; they voluntarily and constantly provide information, beginning with their user profiles and extending to what they like, where they visited, where they are at this moment, what they ate and bought, and much more. ${ }^{48-51}$ Governmental regulation for personal data protection is becoming an acute issue and public concern is growing, but such trends do not yet seem to be causing a decline in the availability of big data to platform operators. The rapid development of highly sophisticated digital marketing in recent years has enabled Facebook partners to obtain data on their target consumers, both aggregated and highly customized for specific purposes (e.g., females aged 35-39, earning between $\mathrm{X}$ and $\mathrm{Y}$ per year, potentially interested in buying property in a certain geographical area), and send personalized advertisements to them.

Targeted marketing online is far more sophisticated than traditional advertising in the old media. Previously, it was impossible to know exactly where target customers could be found 
and how to directly send messages to them. Television commercials, which are very expensive to place, are especially ineffective: Everyone understands that audiences avoid TV commercials, and it is difficult to know how well commercials work for branding or for the promotional effect they are meant for. Broadcasters argue that television is still a very powerful medium for raising awareness of products and services and that its reach is huge in comparison with that of advertising on social media. However, digital marketing agencies contend that social media, too, can be useful for grabbing attention for products and services that users are unaware of and that it is far more effective in encouraging its users to move down the "marketing funnel" to the stage of actual purchase, done seamlessly online. Even if consumers do not continue to the final stage of purchase, it is possible for marketers to track how long users considered a product and/or compared different options and where they abandoned their shopping. It is then possible to retarget lapsed users by digitally sending appropriate messages. In terms of reach as well, social media can be much wider and faster than traditional broadcasting.

\section{Model 6: Digital Marketing Using Self-Operated Sites}

Rather than or in addition to promoting their products or services to users in the social media space, firms in the traditional media industries may earn revenue directly by operating their own sites. It is said that few news sites directly run by legacy media are successful in charging subscription fees in exchange for unlimited access to news content (see Note 9) except for a small number of successes such as the New York Times. ${ }^{52}$ Alternative revenue sources to advertising, such as paywalls, the sale of newspaper apps, crowdfunding, and foundation funding to support news production, have not become viable options (see Note 9). ${ }^{53}$

In this context, the case of Nihon Keizai Shimbun (the Nikkei, a major Japanese financial newspaper) deserves description as an apparently successful example. It is necessary to understand that newspapers are a particularly big business and social institution in Japan with its population of around 130 million. Five national newspapers in Japan, including the Nikkei, boast massive circulations (totaling about twenty million copies in 2018) ${ }^{54}$ that outstrip those in other countries, ${ }^{55}$ alongside numerous regional/local newspapers with a total circulation equivalent to that of the big nationals. The national papers print two editions a day and are mainly delivered through exclusive sales and distribution systems to households that are monthly subscribers. Most importantly, subscription payments' share of total revenue is relatively high, more than half (see Note 54), giving the publishers a stable revenue base. This is an advantaged position compared with that of their Western counterparts who rely on advertising, which is more volatile.

However, a decline in sales of Japanese newspapers to readers and in newspaper advertising has been noticeable, as in other countries, ${ }^{56}$ although no major Japanese newspaper publishers have gone bankrupt as they possess real estate and other assets that provide reliable income. As Villi and Hayashi ${ }^{57}$ discovered, these major newspapers are very protective of the current print media business and reluctant to make a transition to digital. The Nikkei, however, should be given credit for proactively pursuing a digital strategy. The Nikkei has a relatively small circulation of just over 2.4 million, or 4 percent of total households, ${ }^{58}$ compared to giant Yomiuri's 8.5 million, but it enjoys a loyal readership among professionals and those in executive positions, highly-educated, and high-income earners. With its 2015 acquisition 
of the Financial Times (FT), the United Kingdom's top financial paper, the Nikkei has expanded its global scope, distinguishing itself from other newspapers in Japan. In enhancing its position as a financial paper, the Nikkei has been aggressive in its digital strategy and successful in many respects. Free access to online content is allowed to a certain extent, and full access is given for an additional 1,000 yen per month (less than US\$10) to subscribers who are already paying 4,900 yen (about US\$47) per month for a print subscription. A digital-only subscription costs 4,200 yen (about US\$40). The usability of its digital paper on the web and on smartphones is considered excellent and is constantly improved.

As of August 2019, according to the Nikkei website, paying online subscribers number six hundred thousand, while "registered" users number 4.3 million; all have voluntarily supplied personal information regarding their jobs, educational attainment, personal and household income, financial assets, ownership of cars and other properties, holiday preferences, hobbies, and much else. The strength of Nikkei as a publishing group is its broad range of print magazines and online services in business and marketing such as Nikkei CNBC (financial news on television). The company has encouraged readers and service users to register and consolidate their login IDs across these media and services, allowing Nikkei as a group to have a database of 9.3 million unique users. Nikkei online sells advertising space, of course, not just for advertising for all readers like that in the print paper, but also for advertising that targets readers with attributes and interests advertisers are especially looking for. Nikkei's user database, including the very segments of the population that are highly sought-after by many brands, can be matched against that of thirdparty firms, enabling the latter to send out marketing messages to consumers within the relevant Nikkei readership. Such ad technologies and opportunities for digital marketing are not unique to the Nikkei, but the quality of its database allows it to charge advertisers high prices for space. The Nikkei, like other news media, is also venturing into the event and conference business (Business Model 3), which may be marginal as a revenue source but can function to accumulate data on participants and their experiences with advertisers and other client companies.

\section{Conclusion}

The business environment in which the media industries operate has changed greatly because of the development of the internet, the relevant technologies in information, communication and advertising, and devices consumers use to take advantage of advanced ICT. The threat of unlawful content being freely accessible on the web was one factor that undermined the media industries in the late 1990s and early 2000s. Although piracy has not been completely eradicated, a more serious problem is the changed behavior and expectations of consumers and advertisers, two of the revenue sources that have supported the media industries for decades. With consumers less willing to pay for media content unless access to it is convenient for them, and more interested in communicating with other people concerning content, the conventional value chain that starts with the authority and professionalism of media creators and extends through content commodification and distribution to the masses has lost effectiveness. Meanwhile, social media and web spheres offer brands 
ample opportunities for targeted marketing, undermining the dominant position of the traditional media as a place for advertising.

The business model of the media industries - an architecture of value creation that delivers value to targeted customers in exchange for payments that contribute to profit (see Teece in Note 14)-is being adapted and diversified to better match today's changed environment. This article has discussed various responses that the media industries have made, with particular reference to Japanese media. The strategy of 360-degree contracting has become established as a norm among the major global music companies, as has been the case in Japan for a long time. The Japanese idol business in recent decades has contributed greatly to the maintenance of strong packaged (physical) music sales in Japan. While this has been effective in the confined domestic culture of Japan, its global applicability and sustainability are much in question. Diversification and multiplatform application of content, which have been a basis for Hollywood's global success, may still be advancing and increasingly involve partners that are not traditionally associated with the media.

The fifth and sixth new business models that this article has discussed are the most worrying in terms of the status of content and the future vitality of the creative industries, as they value creative content only to the extent that it attracts users whose behavior and profiles are a valuable asset for marketers and other third-party businesses networked in multiple and complex ways. In today's economy, generally, data obtained in Service X may be transmitted through an intermediary platform to Service Y, for which those data are of high value and may well possess potential for innovation. ${ }^{59}$ However, what this means to the media industries seems to be a lowering of the status of content. Content is increasingly seen to be useful mainly as a way to generate and harvest personal and behavioral data on consumers; platform and social media operators have only limited interest in the content itself. The media industries, conceptualized in such a way, are no longer autonomous businesses having their own value chains. Instead, today, they are part of the complex systems of platform and social media operators that link businesses from many sectors to create economic spheres, or "ecosystems," in a new economy based on data-driven innovation. In such an economy, information about users and their behavior is a most important resource and driver of value creation.

It is fair to characterize traditional media businesses as conservative, and if they remain so, IT platform operators with their enormous wealth may take over the domains of the traditionally defined media industries. Change has occurred not only in media consumptioncharacterized by Hesmondhalgh and Meier" as "from domestic consumption to personalized, mobile and connected consumption"-but also in the autonomous space of the media industries in relation to the IT platform operators. The emerging strength of IT giants in media production is epitomized by the Academy Award won by the film ROMA (2018). ROMA was produced by Netflix, which did not possess any particular film production experience or expertise but was able to hire talent and crew who were only too happy to work on creating a film without the budget restrictions and other constraints normally imposed by the film majors. To discuss broader concerns regarding the ever-increasing power of IT platform operators ${ }^{61}$ has been beyond the scope of this article, but such a discussion would surely conclude with some of the same worries and implications that affect the media industries. 
${ }^{1}$ Nobuko Kawashima is professor at Faculty of Economics, Doshisha University. She holds PhD in Cultural Policy (University of Warwick, UK) and MSc in Social Policy and LLM (with distinction), both from the London School of Economics. Her areas of research interest include cultural policy, cultural economics, and the creative/ cultural industries. Her recent publications in English include Kawashima and Lee (eds) (2018), Asian Cultural Flows and Hill and Kawashima (eds) (2017), Film Policy in a Globalized Economy.

${ }^{2}$ David Hesmondhalgh, The Cultural Industries, 4th ed. (Thousand Oaks, CA: SAGE, 2019).

${ }^{3}$ Michael D. Smith and Rahul Telang, Streaming, Sharing, Stealing (Cambridge, MA: MIT Press, 2017), Chapters 2 and 3.

${ }^{4}$ Chris Bilton, The Disappearing Product (Cheltenham: Edward Elgar, 2017).

${ }^{5}$ Nobuko Kawashima, "The Rise of User Creativity-Web 2.0 and a New Challenge for Copyright Law and Cultural Policy," International Journal of Cultural Policy 16 (3, 2010): 337-53.

${ }^{6}$ Henry Jenkins, Convergence Culture (NY: New York University Press, 2007).

${ }^{7}$ Henry Jenkins, Sam Ford, and Joshua Green, Spreadable Media (NY: New York University Press, 2013).

${ }^{8}$ Elizabeth Bird, "'Are We All Produsers Now?' Convergence and Media Audience Practices," Cultural Studies 25 (4-5, 2011): 502-16.

${ }^{9}$ Bob Franklin, "The Future of Journalism: In an Age of Digital Media and Economic Uncertainty," Journalism Practice 8 (5, 2014): 469-87.

${ }^{10}$ Stan J. Liebowitz, "File Sharing: Creative Destruction or Just Plain Destruction?" The Journal of Law and Economics 49 (1, 2006): 1-28.

${ }^{11}$ Nils Wlömert and Dominik Papies, "On-Demand Streaming Services and Music Industry Revenues-Insights from Spotify's Market Entry," International Journal of Research in Marketing 33 (2016): 314-27.

${ }^{12}$ Pierre-Jean Benghozi and Françoise Benhamou, "The Long Tail: Myth or Reality?" International Journal of Arts Management 12 (3, 2010): 43-53.

${ }^{13}$ Erik Brynjolfsson, Yu Hu, and Michael D. Smith, "Long Tails vs. Superstars: The Effect of Information Technology on Product Variety and Sales Concentration Patterns," Information Systems Research 21 (4, 2010): 736-47.

14 The term "business model" has been ill-defined despite its increasing popularity among business studies researchers and scholars. To fully examine and discuss various usages of the term is beyond the scope of this article. The definition I use in this article follows the discussion in David J. Teece, "Business Models, Business Strategy and Innovation," Long Range Planning 43 (2010): 172-94.

${ }^{15}$ Vasco Eiriz and Filipe Pinto Leite, "The Digital Distribution of Music and Its Impact on the Business Models of Independent Musicians," The Service Industries Journal 37 (13-14, 2017): 875-95.

${ }^{16}$ Patrik Wilkström, "The Adaptive Behavior of Music Firms: A Music Industry Feedback Model," Journal of Media Business Studies 6 (2, 2009): 67-96.

17 Tom Evens, "Value Networks and Changing Business Models for the Digital Television Industry," The Journal of Media Business Studies 7 (4, 2010): 41-58. 
${ }^{18}$ Nicola Searle, Changing Business Models in the Creative Industries: The Cases of Television, Computer Games and Music. Report commissioned by the Intellectual Property Office (UK). London: IPO, 2011.

${ }^{19}$ Christoph Zott, Raphael Amit, and Lorenzo Massa, "The Business Model: Recent Developments and Future Research," Journal of Management 37 (4, 2011): 1019-42.

${ }^{20}$ Nobuko Kawashima, "Film Policy in Japan-An Isolated Species on the Verge of Extinction?" International Journal of Cultural Policy 22 (5, 2016): 787-804.

${ }^{21}$ Michael Curtin, "Media Capital: Towards the Study of Spatial Flows," International Journal of Cultural Studies 6 (2, 2003): 202-28.

${ }^{22}$ Thomas Hess, "What Is a Media Company? A Reconceptualization for the Online World," The International Journal on Media Management 16 (2014): 3-8.

${ }^{23}$ Nancy K. Baym, "The Swedish Model: Balancing Markets and Gifts in the Music Industry," Popular Communication 9 (2011): 22-38.

${ }^{24}$ Paul G. Oliver, "The DIY Artist: Issues of Sustainability within Local Music Scenes," Management Decision 48 (9, 2010): 1422-32.

${ }^{25}$ Daniel A. Walzer, "Independent Music Production: How Individuality, Technology and Creative Entrepreneurship Influence Contemporary Music Industry Practices," Creative Industries Journal 10 (1, 2017): 21-39.

${ }^{26}$ The changing nature of fandom in the digital economy has been debated in fandom studies (see Pearson 2010).

${ }^{27} \mathrm{Jim}$ Rogers and Sergio Sparviero, "Understanding Innovation in Communication Industries through Alternative Economic Theories: The Case of the Music Industry," The International Communication Gazette 73 (7, 2011): 610-29.

${ }^{28}$ Hwanho Choi and Bernard Burnes, "The Internet and Value Co-Creation: The Case of the Popular Music Industry," Prometheus 31 (1, 2013): 35-53.

${ }^{29}$ Patryk Galuszka, "New Economy of Fandom," Popular Music and Society 38 (1, 2015): 25-43.

${ }^{30}$ Jeremy Wade Morris, "Artists as Entrepreneurs, Fans as Workers," Popular Music and Society 37 (3, 2014): 273-90.

31 There is also a concern that royalty payments made from streaming services to artists are too small (Lee Marshall, "Let's Keep Music Special. F-Spotify': On-Demand Streaming and the Controversy Over Artist Royalties," Creative Industries Journal 8 (2, 2015): 177-89.

${ }^{32}$ Patryk Galuszka, "Music Aggregators and Intermediation of the Digital Music Market," International Journal of Communication 9 (2015): 254-73.

${ }^{33}$ David Arditi, "iTunes: Breaking Barriers and Building Walls," Popular Music and Society 37 (4, 2014): 408-24.

${ }^{34}$ Leslie M. Meier, Popular Music as Promotion. Music and Branding in the Digital Age (Cambridge: Polity, 2017).

${ }^{35}$ Zack O'Malley Greenburg, "The World's Highest-Paid Musicians of 2015," Forbes, December 8, 2015. https://www.forbes.com/sites/zackomalleygreen burg/2015/12/08/the-worlds-highest-paid-musicians-of-2015/\#7127e2611a22 (accessed August 15, 2019). 
${ }^{36}$ Lee Marshall, 'The 360 Deal and the "New' Music Industry," European Journal of Cultural Studies 16 (1, 2012): 77-99.

${ }^{37}$ David W. Marx, "The Jimusho System: Understanding the Production Logic of the Japanese Entertainment Industry," in Idols and Celebrity in Japanese Media Culture, ed. Patrick W. Galbraith and Jason G. Karlin (Basingstoke: Palgrave Macmillan, 2012), 35-55.

${ }^{38}$ Sumiko Asai, "Firm Organisation and Marketing Strategy in the Japanese Music Industry," Popular Music 27 (3, 2008): 473-85.

${ }^{39}$ Patrick W. Galbraith and Jason G. Karlin, "Introduction: The Mirror of Idols and Celebrity," in Idols and Celebrity in Japanese Media Culture, ed. Patrick W. Galbraith and Jason G. Karlin (Basingstoke: Palgrave Macmillan, 2012), 1-32.

${ }^{40}$ Tim Craig, Cool Japan-Case Studies from Japan's Cultural and Creative Industries (Boulder, CO: Blue Sky Publishing, 2017).

${ }^{41}$ Record Industry Association of Japan. https://www.riaj.or.jp/True/?requestLocale = en (accessed August 15, 2019).

${ }^{42}$ IFPI. Global Statistic, 2019. https://www.ifpi.org/facts-and-stats.php (accessed August 15, 2019).

${ }^{43}$ Nobuko Kawashima, "Advertising Agencies, Media and Consumer Market: The Changing Quality of TV Advertising in Japan," Media, Culture and Society 28 (3, 2006): 393-410.

${ }^{44}$ Jason G. Karlin, "Through a Looking Glass Darkly: Television Advertising, Idols, and the Making of Fan Audiences," in Idols and Celebrity in Japanese Media Culture, ed. Patrick W. Galbraith and Jason G. Karlin (Basingstoke: Palgrave Macmillan, 2012).

${ }^{45}$ Lucy Glasspool, "From Boys Next Door to Boys' Love: Gender Performance in Japanese Male Idol Media," in Idols and Celebrity in Japanese Media Culture, ed. Patrick W. Galbraith and Jason G. Karlin (Basingstoke: Palgrave Macmillan, 2012), 113-30.

${ }^{46}$ Mark Fox and Bruce Wrenn, "A Broadcasting Model for the Music Industry," The International Journal of Media Management 3 (2, 2001): 112-19.

${ }^{47}$ Ingyu Oh and Gil-Sung Park, "From B2 C to B2B: Selling Korean Pop Music in the Age of New Social Media," Korea Observer 433, 2012): 365-97.

${ }^{48}$ Christina Alaimo and Jannis Kallinikos, "Computer the Everyday: Social Media as Data Platforms," The Information Society 33 (4, 2017): 175-91.

${ }^{49}$ Jens-Erik Mal, "Big Data Privacy: The Datafication of Personal Information," The Information Society 32 (3, 2016): 192-99.

${ }^{50}$ Jose van Dijck, The Culture of Connectivity (Oxford: Oxford University Press, 2013).

${ }^{51}$ Rowan Wilken, "Places Nearby: Facebook as a Location-based Social Media Platform," New Media \& Society 16 (7, 2014): 1087-1103.

${ }^{52}$ Lucy Küng, Innovators in Digital News (London: I.B. Tauris, 2015).

${ }^{53}$ Tom Evens, Tim Raats, and M. Bjørn von Rimscha, "Business Model Innovation in News Media Organisations-2018 Special Issue of the European Media Management Association," Journal of Media Business Studies 14 (3, 2017): 167-72.

${ }^{54}$ Dentsu, Jouhou Medhia Hakusho [White Paper on Information and Media] (Tokyo, Japan: Diamond Publishing, 2019). (in Japanese) 
${ }^{55}$ According to data from the Nihon Shinbun Kyokai (Japan Association of Newspaper Publishers), Japan published 381.4 copies per 1,000 adults in 2017 , the highest number in the world, followed by Germany (201.5 copies) and the Netherlands (174.3 copies).

${ }^{56}$ Circulations declined from 53.7 million copies in 2000 to 39.9 million in 2008 for general newspapers and "sports newspapers" (similar to tabloids in the West) combined.

${ }^{57}$ Mikko Villi and Kaori Hayashi, “"The Mission is to Keep This Industry Intact' Digital Transition in the Japanese Newspaper Industry," Journalism Studies 18 (8, 2017): 960-77.

${ }^{58}$ Nikkei, Online Edition Media Guide and Specifications. 2019, https://ps.nikkei .co.jp/adweb/english/download/?_ga=2.42720165.1898436580.1565598016749819087.1550632120 (accessed August 11, 2019).

${ }^{59}$ OECD, Data-Driven Innovation: Big data for growth and well-being (Paris: OECD, 2017).

${ }^{60}$ David Hesmondhalgh and Leslie M. Meier, "What the Digitalisation of Music Tells Us about Capitalism, Culture and the Power of the Information Technology Sector," Information, Communication and Society 21 (11, 2018): 1555-70.

${ }^{61}$ Nick Srnicek, Platform Capitalism (Cambridge: Polity, 2016).

\section{Bibliography}

Alaimo, Christina, and Jannis Kallinikos. "Computer the Everyday: Social Media as Data Platforms." The Information Society 33, no. 4 (2017): 175-91.

Arditi, David. "iTunes: Breaking Barriers and Building Walls." Popular Music and Society 37, no. 4 (2014): 408-24.

Asai, Sumiko. "Firm Organisation and Marketing Strategy in the Japanese Music Industry." Popular Music 27, no. 3 (2008): 473-85.

Baym, Nancy K. "The Swedish Model: Balancing Markets and Gifts in the Music Industry." Popular Communication 9 (2011): 22-38.

Benghozi, Pierre-Jean, and Françoise Benhamou. "The Long Tail: Myth or Reality?" International Journal of Arts Management 12, no. 3 (2010): 43-53.

Bilton, Chris. The Disappearing Product. Cheltenham: Edward Elgar, 2017.

Bird, Elizabeth. "'Are We All Produsers Now?' Convergence and Media Audience Practices." Cultural Studies 25, no. 4-5 (2011): 502-16.

Brynjolfsson, Erik, Yu Hu, and Michael D. Smith. "Long Tails vs. Superstars: The Effect of Information Technology on Product Variety and Sales Concentration Patterns." Information Systems Research 21, no. 4 (2010): 736-47.

Choi, Hwanho, and Bernard Burnes. "The Internet and Value Co-Creation: The Case of the Popular Music Industry." Prometheus 31, no. 1 (2013): 35-53. 
Craig, Tim. Cool Japan-Case Studies from Japan's Cultural and Creative Industries. Boulder, CO: Blue Sky Publishing, 2017.

Curtin, Michael. "Media Capital: Towards the Study of Spatial Flows." International Journal of Cultural Studies 6, no. 2 (2003): 202-28.

Dentsu. Jouhou Medhia Hakusho [White Paper on Information and Media]. Tokyo, Japan: Diamond Publishing, 2019. (in Japanese)

Eiriz, Vasco, and Filipe Pinto Leite. "The Digital Distribution of Music and Its Impact on the Business Models of Independent Musicians." The Service Industries Journal 37, no. 13-14 (2017): 875-95.

Evens, Tom. "Value Networks and Changing Business Models for the Digital Television Industry." The Journal of Media Business Studies 7, no. 4 (2010): 41-58.

Evens, Tom, Tim Raats, and M. Bjørn von Rimscha. "Business Model Innovation in News Media Organisations-2018 Special Issue of the European Media Management Association." Journal of Media Business Studies 14, no. 3 (2017): 167-72.

Fox, Mark, and Bruce Wrenn. "A Broadcasting Model for the Music Industry." The International Journal of Media Management 3, no. 2 (2001): 112-19.

Franklin, Bob. "The Future of Journalism: In an Age of Digital Media and Economic Uncertainty." Journalism Practice 8, no. 5 (2014): 469-87.

Galbraith, Patrick W., and Jason G. Karlin. "Introduction: The Mirror of Idols and Celebrity." In Idols and Celebrity in Japanese Media Culture, edited by Patrick W. Galbraith and Jason G. Karlin, 1-32. Basingstoke: Palgrave Macmillan, 2012.

Galuszka, Patryk. "Music Aggregators and Intermediation of the Digital Music Market." International Journal of Communication 9 (2015a): 254-73.

Galuszka, Patryk. "New Economy of Fandom." Popular Music and Society 38, no. 1(2015b): 25-43.

Gerlitz, Carolin, and Anne Helmond. "The Like Economy: Social Buttons and the DataIntensive Web." New Media \& Society 15, no. 8 (2013): 1348-65.

Glasspool, Lucy. "From Boys Next Door to Boys' Love: Gender Performance in Japanese Male Idol Media." In Idols and Celebrity in Japanese Media Culture, edited by Patrick W. Galbraith and Jason G. Karlin, 113-30. Basingstoke: Palgrave Macmillan, 2012.

Greenburg, Zack O’Malley. "The World's Highest-Paid Musicians of 2015." Forbes, December 8, 2015. https://www.forbes.com/sites/zackomalleygreenburg/2015/12/08/theworlds-highest-paid-musicians-of-2015/\#7127e2611a22 (accessed August 15, 2019).

Hesmondhalgh, David. The Cultural Industries, 4th ed. Thousand Oaks, CA: SAGE, 2019.

Hesmondhalgh, David, and Leslie M. Meier. "What the Digitalisation of Music Tells Us about Capitalism, Culture and the Power of the Information Technology Sector." Information, Communication and Society 21, no. 11 (2018): 1555-70.

Hess, Thomas. "What Is a Media Company? A Reconceptualization for the Online World." The International Journal on Media Management 16 (2014): 3-8.

IFPI. Global Statistic, 2019. https://www.ifpi.org/facts-and-stats.php (accessed August 15, 2019). 
Jenkins, Henry. Convergence Culture. New York: New York University Press, 2007.

Jenkins, Henry, Sam Ford, and Joshua Green. Spreadable Media. New York: New York University Press, 2013.

Kawashima, Nobuko. "Advertising Agencies, Media and Consumer Market: The Changing Quality of TV Advertising in Japan." Media, Culture and Society 28, no. 3 (2006): 393-410.

Kawashima, Nobuko. "Film Policy in Japan-An Isolated Species on the Verge of Extinction?" International Journal of Cultural Policy 22, no. 5 (2016): 787-804.

Kawashima, Nobuko. "The Rise of User Creativity-Web 2.0 and a New Challenge for Copyright Law and Cultural Policy." International Journal of Cultural Policy 16, no. 3 (2010): 337-53.

Küng, Lucy. Innovators in Digital News. London: I.B. Tauris, 2015.

Liebowitz, Stan J. "File Sharing: Creative Destruction or Just Plain Destruction?" The Journal of Law and Economics 49, no. 1 (2006): 1-28.

Mal, Jens-Erik. "Big Data Privacy: The Datafication of Personal Information." The Information Society 32, no. 3 (2016): 192-99.

Marshall, Lee. "The 360 Deal and the 'New' Music Industry." European Journal of Cultural Studies 16, no. 1 (2012): 77-99.

Marshall, Lee. "Let's Keep Music Special. F-Spotify': On-Demand Streaming and the Controversy over Artist Royalties." Creative Industries Journal 8, no. 2 (2015): 177-89.

Marx, David W. "The Jimusho System: Understanding the Production Logic of the Japanese Entertainment Industry." In Idols and Celebrity in Japanese Media Culture, edited by Patrick W. Galbraith and Jason G. Karlin, 35-55. Basingstoke: Palgrave Macmillan, 2012.

Meier, Leslie M. Popular Music as Promotion. Music and Branding in the Digital Age. Cambridge: Polity, 2017.

Morris, Jeremy Wade. "Artists as Entrepreneurs, Fans as Workers." Popular Music and Society 37, no. 3 (2014): 273-90.

Newman, John M. "Copyright Freeconomics." Vanderbilt Law Review 66 (2013): 1409-69.

Nikkei. Online Edition Media Guide and Specifications. 2019. https://ps.nikkei.co.jp/adweb/ english/download/?_ga=2.42720165.1898436580.1565598016-749819087.1550632120 (accessed August 11, 2019).

OECD. Data-Driven Innovation: Big data for growth and well-being. Paris: OECD, 2017.

Oh, Ingyu, and Gil-Sung Park. "From B2C to B2B: Selling Korean Pop Music in the Age of New Social Media." Korea Observer 43, no. 3(2012): 365-97.

Oliver, Paul G. "The DIY Artist: Issues of Sustainability within Local Music Scenes." Management Decision 48, no. 9 (2010): 1422-32.

Pearson, Roberta. "Fandom in the Digital Era." Popular Communication 8 (2010): 84-93.

Picard, Robert G. "Twilight or New Dawn of Journalism? Evidence from the Changing News Ecosystem." Journalism Practice 8, no. 5 (2014): 488-98. 
Record Industry Association of Japan. https://www.riaj.or.jp/e/?requestLocale=en (accessed August 15, 2019).

Rogers, Jim, and Sergio Sparviero. "Understanding Innovation in Communication Industries through Alternative Economic Theories: The Case of the Music Industry." The International Communication Gazette 73, no. 7 (2011): 610-29.

Searle, Nicola. Changing Business Models in the Creative Industries: The Cases of Television, Computer Games and Music. Report commissioned by the Intellectual Property Office (UK). London: IPO, 2011.

Smith, Michael D., and Rahul Telang. Streaming, Sharing, Stealing. Cambridge, MA: MIT Press, 2017.

Srnicek, Nick. Platform Capitalism. Cambridge: Polity, 2016.

van Dijck, Jose. The Culture of Connectivity. Oxford: Oxford University Press, 2013.

Villi, Mikko, and Kaori Hayashi. “The Mission is to Keep This Industry Intact' Digital Transition in the Japanese Newspaper Industry." Journalism Studies 18, no. 8 (2017): 960-77.

Walzer, Daniel A. "Independent Music Production: How Individuality, Technology and Creative Entrepreneurship Influence Contemporary Music Industry Practices." Creative Industries Journal 10, no. 1 (2017): 21-39.

Wilken, Rowan. "Places Nearby: Facebook as a Location-based Social Media Platform." New Media \& Society 16, no. 7 (2014): 1087-1103.

Wilkström, Patrik. "The Adaptive Behavior of Music Firms: A Music Industry Feedback Model." Journal of Media Business Studies 6, no. 2 (2009): 67-96.

Wlömert, Nils, and Dominik Papies. "On-Demand Streaming Services and Music Industry Revenues-Insights from Spotify's Market Entry." International Journal of Research in Marketing 33 (2016): 314-27.

Zott, Christoph, Raphael Amit, and Lorenzo Massa. "The Business Model: Recent Developments and Future Research." Journal of Management 37, no. 4 (2011): 1019-42. 